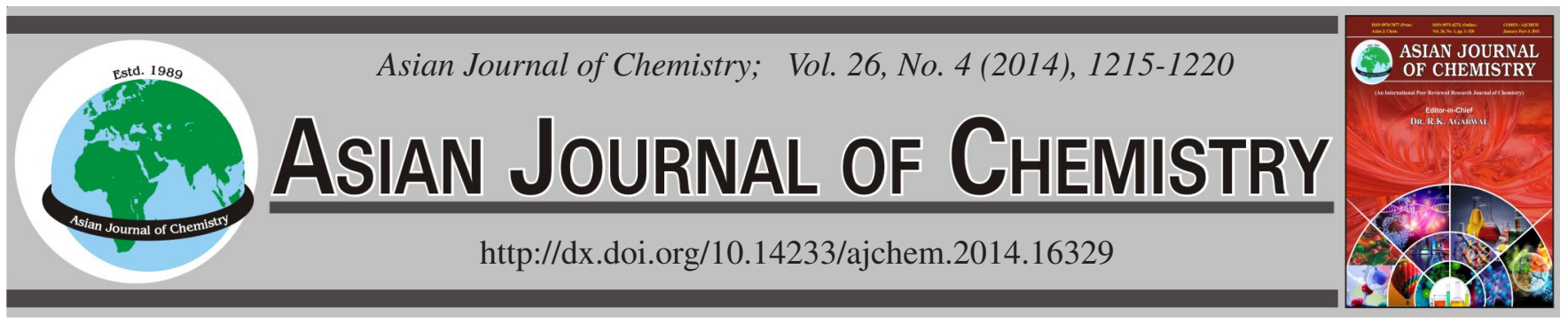

\title{
Optimization Process of Total Phenol from Suaeda glauca Bge Leaf by Response Surface Methodology and Free Radical Scavenging Activity of Extract
}

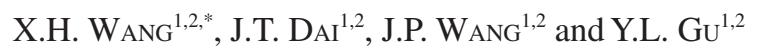

${ }^{1}$ Jiangsu Provincial Key Laboratory of Coastal Wetland Bioresources and Environmental Protection, Department of Chemistry, Yancheng Teachers University, Xiwang Road, Yancheng 224051, Jiangsu Province, P.R. China

${ }^{2}$ Institute of Applied Chemistry \& Environmental Engineering, Department of Chemistry, Yancheng Teachers University, Yancheng 224051, Jiangsu Province, P.R. China

*Corresponding author: Tel: +86 515 88233187; E-mail: wangxhong1227@163.com

Suaeda glauca Bge leaf extract was evaluated for total phenolic content and antioxidant capacity. The extraction process of total phenolics based microwave-assisted extraction was optimized by single-factor experiment and response surface methodology, which parameters included the solid-liquid ratio, extraction time and extraction cycle. Under the optimized experimental conditions, the best results were obtained that in highest extraction total phenolic content was $2624.29 \mathrm{ug} \mathrm{g}^{-1}$ with microwave time for 68.34 min, liquid-solid ratio for $62.33 \mathrm{~mL} \mathrm{~g}^{-1}$ and three time extraction. The proposed microwave-assisted extraction was an efficient extraction procedure with shorter extraction time and remarkable higher efficiencies. The assay of antioxidant capacity contained potential free radical scavenging activities for 1,1-diphenyl-2-picrylhydrazyl free radical (DPPH), hydroxyl radical $(\mathrm{OH})$, superoxide radicals $\left(\mathrm{O}_{2}^{-}\right)$and hydrogen peroxide $\left(\mathrm{H}_{2} \mathrm{O}_{2}\right)$, which compared with standards VC/BHT. The present study indicated that Suaeda glauca Bge leaf possess a strong anti-radical activity and may be considering to make efforts in the oxidation resistance of application.

Keywords: Microwave-assisted extraction, Antiradical, Response surface methodology, Total phenols.
\end{abstract}

\section{INTRODUCTION}

Suaeda glauca Bge. (Chenopodiaceae) is also known as Suaeda sulsa. It is an annual and wild herb on the seashore or salt flats, which is a typical indicator plants. More than 100 kinds of S. glauca are widely distributed in Asia and Europe, etc. and mainly have growth in the northeast of China and the beach, desert, grassland, lake, river, land and salt-rich soil of the coastal provinces. S. glauca is rich in nutrition, no-pollution and known as "green food "1.

Phenols are the most widely distributed in the most natural plant, which possess biological diversity ${ }^{2}$. They have the physiological functions of multiple antioxidant activity and prevention of cardiovascular diseases ${ }^{3}$. According to the different extraction solvents, extraction methods of phenols can be divided into organic solvent extraction, supercritical $\mathrm{CO}_{2}$ extraction ${ }^{4}$, enzyme extraction and ionic liquids extraction, etc. In addition, the traditional extraction process is complex, time consuming to lead to low extraction yield because of easy oxidation of phenols substances. High pressure liquid chromatography can be used to improve the extraction efficiency, but it is difficult to realize continuous industrial production. In recent years, microwave technology has been widely applied in extraction field of active ingredients in natural plant since that it has the significant advantages of high efficiency, fast, energy-saving ${ }^{5}$. Meanwhile it has being replaced the traditional reflux extraction and ultrasonic extraction method to be the most widely adopted method.

Excessive production and too low clean of oxygen free radical have a close connection with cell injury and disease, such as atherosclerosis, diabetes, liver disease, aging, cancer etc. With the oxygen free radical and antioxidant theory research, the use of synthetic antioxidants has been restricted by many countries. It is the focus on searching for effective, low toxicity from natural sources of natural antioxidants. So far the reports on S. glauca are relatively few about the extraction of active compounds and antioxidant potential.

The present study, therefore has aiming at studying a microwave extraction process of total phenols, optimization of process parameters using single factor experiment and response surface method using the total phenolic content as the evaluation index to examine the parameters of extraction process and in vitro free radical scavenging potential of $S$. glauca. This could be to provide theoretical basis for the feasible development of $S$. glauca as a natural source of antioxidants and the health food. 


\section{EXPERIMENTAL}

Pyrogallol, ascorbic acid, gallic acid and Folin-Ciocalteu phenol reagent were bought from Sinopharm Chemical Reagent Co. (Shanghai, China). 1,10-Phenanthroline monohydrate were also obtained from ShanPu Chemical Co., Ltd. (Shanghai, China). Ferrous sulfate and citric acid were purchased from Yixing Second Chemical Reagent Factory (Jiangsu, China). 1,1-Diphenyl-2-picrylhydrazyl free radical was bought from TCI Chemical Industry Development Co., Ltd. (Shanghai, China). Ethanol was got from Tong Sheng Chemical Reagent Co., Ltd. (Jiangsu, China). The above samples were analytical grade. 2,6-Ditertbutyl-4-methyl phenol (BHT) was guarantee reagent and supplied by GuangFu Chemical Reagents Co. (Tianjin, China). S. glauca leaf was picked from seawalls in Dafeng city (Jiangsu, China). The $S$. glauca leaf were cleaned and dried under vacuum at $60{ }^{\circ} \mathrm{C}$ for over $48 \mathrm{~h}$, then they were ground into a fine powder in a mill and stored in closed desiccators at $4{ }^{\circ} \mathrm{C}$ until use.

UV-visible spectrophotometer (SPECORD-50, Jena, Germany) was used for the determination of total phenolic content and antioxidant activities. A rotary evaporator (R201DII, Shanghai, China) was used to remove water, ethanol and other impurities. KQ-300E ultrasonic cleaner (Kunshan, Jiangsu, China) were a rectangular container used in the extraction step. The generators of these ultrasonic water baths have frequency of $40 \mathrm{kHz}$. High speed centrifugation (800, Shanghai, China) was employed to accelerate the phase separation process. A plant material was pulverized by the Joyoung soybean machine (DJ13B-D18D, Shandong, China) into powder for next extraction procedure.

Standard curve and total phenols of sample: Gallic acid $(0.1000 \mathrm{~g})$ was accurately weighed and mixed with distilled water and diluted the solution to $100 \mathrm{~mL}$ in a volumetric flask. $1,2,3,4,5,6,7$ and $8 \mathrm{~mL}$ of gallic standard solutions were taken again and diluted to $100 \mathrm{~mL}$ by adding distilled water. And then 10, 20, 30, 40, 50, 60, 70 and $80 \mu \mathrm{g} \mathrm{mL} \mathrm{m}^{-1}$ of gallic acid solution were got and respectively added $1 \mathrm{~mL}$ FolinCiocalteu phenol reagent, followed by adding $3 \mathrm{~mL}$ of $7.5 \%$ sodium carbonate solution for $0.5 \mathrm{~h}$ at $25^{\circ} \mathrm{C}$ in darkness. The absorbance at $765 \mathrm{~nm}$ was recorded and the standard curve between absorbance and gallic acid concentration was plotted. The standard equation was $\mathrm{y}=52.121 \mathrm{x}-8.5872, \mathrm{R}^{2}=0.9912$, $\mathrm{x}$ was absorbance and $\mathrm{y}$ was the concentration of gallic acid ( $\mu \mathrm{g}$ GAE $\left.\mathrm{mL}^{-1}\right)$.

Folin-Ciocalteu phenol reagent method was used for analyzing total phenol content of $S$. glauca leaf extract according to the method ${ }^{6}$. The sample $1 \mathrm{~mL}$ of $S$. glauca leaf extract was mixed with $1 \mathrm{~mL}$ Folin-Ciocalteu reagent and then added $3 \mathrm{~mL}$ of $7.5 \%$ sodium carbonate solution, stayed for $0.5 \mathrm{~h}$ at $25^{\circ} \mathrm{C}$ in darkness. Then the absorbance at $765 \mathrm{~nm}$ was scanned. Total phenol contents in the sample extract was calculated through the standard equation. Total phenol content (TPC) from $S$. glauca leaf was determined as follows:

Total phenol content $\left(\mu \mathrm{g}\right.$ GAE g $\left.{ }^{-1}\right)=(52.121 \mathrm{x}-8.5872)$ $\left(\mathrm{mg} \mathrm{mL}^{-1}\right) \times$ solvent volume $(\mathrm{mL}) \times$ dilution ratio $\times 1000 /$ mean mass of the dried samples $(\mathrm{g})$.

Single-factor experiment of extraction of total phenols in sample: Accurately weighed $S$. glauca leaf $1 \mathrm{~g}$ was put into a flask by adding a certain concentration of ethanol aqueous solution $(30,50,70,90,100 \%, \mathrm{v} / \mathrm{v})$ with the certain ratio of solid-liquid $(1: 10,1: 20,1: 30,1: 40: 1: 50)$. Then the flask was placed into the ultrasonic cleaning bath, followed by sonication for a certain time $(20,40,6080,100 \mathrm{~min})$ at different temperatures $\left(30,40,50,60,70{ }^{\circ} \mathrm{C}\right)$. The ethanolic concentration, solid-liquid ratio, extraction time and extraction temperature were all factors for investigation. An optimal parameter in every factor was selected to further study the interaction between the experimental factors with response surface methodology (RSM).

Optimization experimental by response surface method (RSM): Response surface methodology was employed for further studying the interaction between the factors. The BoxBehnken Design method which is often used in it was selected to apply in data processing using Design-Expert 7.0 software.

Free radical scavenging activity of $S$. glauca leaf extract: According to the optimal condition modified (microwave time $68 \mathrm{~min}$, liquid-solid ratio $62 \mathrm{~mL} \mathrm{~g}^{-1}$ and three time extraction). The weighed $S$. glauca leaf $1 \mathrm{~g}$ was extracted three-times in the ultrasonic cleaner with $50 \mathrm{~mL}$ of $70 \%$ ethanol in a flask (50 mL). The stock solution of $20 \mathrm{mg} \mathrm{mL}^{-1}$ was got to test the antioxidant activity.

Activity of scavenging 1,1-diphenyl-2-picrylhydrazyl radical: 1,1-Diphenyl-2-picrylhydrazyl free radical scavenging activity of extracts was measured by bleaching the purplecolored ethanol solution of the stable 1,1-diphenyl-2-picrylhydrazyl radical, according to the known method $^{7}$. The decrease in absorbance was measured at $517 \mathrm{~nm}$ against a blank without extract using a spectrophotometer. This method was described in previous studies ${ }^{8}$. The capability to scavenge the 1,1-diphenyl2-picrylhydrazyl free radical was calculated using the following equation: 1,1-diphenyl-2-picrylhydrazyl $(\%)=$ $\left(\mathrm{A}_{0}-\mathrm{A}_{\mathrm{i}}\right) \times 100 / \mathrm{A}_{0}$, where $\mathrm{A}_{0}$ is the initial concentration of the stable 1,1-diphenyl-2-picrylhydrazyl radical without the test compound and $A_{i}$ is the absorbance of the remaining concentration of 1,1-diphenyl-2-picrylhydrazyl in the extracts. The 1,1-diphenyl-2-picrylhydrazyl (\%) values were plotted against the extract concentrations and a linear regression curve was established to obtain the $\mathrm{IC}_{50}$. It is the concentration in $\mathrm{mg}$ of dry sample per $\mathrm{mL}$ that is required to quench $50 \%$ of the initial 1,1-diphenyl-2-picrylhydrazyl radicals under the experimental conditions given. Also, freshly made BHT methanol solution and aqueous ascorbic acid solution of different concentrations were analyzed for their 1,1-diphenyl2-picrylhydrazyl (\%) to compare the $\mathrm{IC}_{50}$ value with the extract of $S$. glauca leaf.

Activity of scavenging hydroxyl radical: The assay for hydroxyl radical $(\mathrm{OH})$ scavenging activity was determined using the known methods ${ }^{9}$. Briefly, $1 \mathrm{~mL}$ of $2.5 \mathrm{mmol} \mathrm{L}^{-1} 1,10$ phenanthroline monohydrate was dissolved in $2 \mathrm{~mL}$ phosphate buffer $\left(\mathrm{pH}=8,0.2 \mathrm{~mol} \mathrm{~L}^{-1}\right)$ and $1 \mathrm{~mL}$ double-distilled water. After shaking, one milliliter of $2.5 \mathrm{mmol} \mathrm{L}^{-1}$ ferrous sulfate and $1 \mathrm{~mL}$ of $20 \mathrm{mmol} \mathrm{L}^{-1}$ hydrogen peroxide were added into the system above, which was incubated in a constant temperature bath at $37^{\circ} \mathrm{C}$. After $1 \mathrm{~h}$, the absorbance measured at $536 \mathrm{~nm}$ was $\mathrm{A}_{\mathrm{c}}$. The hydroxyl radical scavenging activity of the extracts was calculated according to the equation: 


$$
\mathrm{OH}(\%)=\left(\mathrm{A}_{\mathrm{s}}-\mathrm{A}_{\mathrm{c}}\right) \times 100 /\left(\mathrm{A}_{\mathrm{wc}}-\mathrm{A}_{\mathrm{c}}\right)
$$

where $A_{c}$ is the absorbance of system solution, $A_{w c}$ is the absorbance of the system with $1 \mathrm{~mL} 20 \mathrm{mmol} \mathrm{L}^{-1}$ hydrogen peroxide replaced by $1 \mathrm{~mL}$ double-distilled water and as is the absorbance with $1 \mathrm{~mL} 20 \mathrm{mmol} \mathrm{L}^{-1}$ hydrogen peroxide replaced by $1 \mathrm{~mL}$ extract.

Activity of inhibiting superoxide anion radical: The superoxide anion radical from pyrogallol auto-oxidation reaction was tested using a UV Spectrophotometer according to the literature documented with slightly modifications ${ }^{10}$. Briefly, the different volume of stock solution $(0.2,0.4,0.6$, $0.8,1.0,1.2,1.4,1.6 \mathrm{~mL}$ ) was diluted to a appropriate volume $(10 \mathrm{~mL})$ in the flask with $70 \%$ ethanol. Then $1 \mathrm{~mL}$ of each extracts was taken individually and dissolved in $3 \mathrm{~mL}$ of phosphate buffer solution $\left(100 \mathrm{mmol} \mathrm{L}^{-1}, \mathrm{pH}=8.2\right)$ to react for $0.5 \mathrm{~h}$ at $25{ }^{\circ} \mathrm{C}$. After $0.4 \mathrm{~mL}$ of pyrogallol solution $(4.5$ mmol $\mathrm{L}^{-1}$ ) added into the reaction system, the mixed solution were quickly shaken. The absorbance at $320 \mathrm{~nm}$ was measured at an interval of $30 \mathrm{~s}$ against a blank. The inhibiting effect of superoxide anion radical was calculated with the following equation:

$$
\mathrm{O}_{2}^{-}(\%)=\left(\Delta \mathrm{A}_{0}-\Delta \mathrm{A}\right) \times 100 / \Delta \mathrm{A}_{0}
$$

where $\Delta \mathrm{A}_{0}$ is the auto-oxidant rate without the extract and $\Delta \mathrm{A}$ is the auto-oxidant rate with the extract the extracts.

Activity of scavenging hydrogen peroxide: The assay for hydrogen peroxide in fruit extracts of strawberry was carried out following procedures previously described by the method $^{11}$. The extract $(4 \mathrm{~mL})$ was mixed with $0.6 \mathrm{~mL}$ of 4 mmol L ${ }^{-1} \mathrm{H}_{2} \mathrm{O}_{2}$ solution prepared in phosphate beffer $(0.1 \mathrm{~mol}$ $\mathrm{L}^{-1}, \mathrm{pH}=7.4$ ) and incubated for $10 \mathrm{~min}$. The absorbance was measured at $230 \mathrm{~nm}$ against blank solution containing the plant extract without $\mathrm{H}_{2} \mathrm{O}_{2}$.

\section{RESULTS AND DISCUSSION}

\section{Single factor experiment of total phenolic contents}

Effect of ratio of liquid-solid: The ratio of liquid-solid evidently can influence extraction efficiency due to the different contact area of liquid and solid. Fig. 1a illustrated that the ratio of liquid-solid lower than $50 \mathrm{~mL} \mathrm{~g}^{-1}$ can lead to immerse incompletely, so there was relatively low total phenolic contents, whereas the ratio of liquid-solid higher than $50 \mathrm{~mL} \mathrm{~g}^{-1}$ caused dilution of the extractive and thus lower total phenolic contents. Therefore, a ratio of liquid-solid range of $40-80 \mathrm{~mL} \mathrm{~g}^{-1}$ was selected in the further optimization experiments.

Effect of extraction time on extraction efficiency: To some extent, the microwave extraction time plays another important role in the extraction process. Fig. $1 \mathrm{~b}$ showed that the extraction efficiencies of total phenols increased with increasing irrational time up to $30 \mathrm{~s}$. When the irrational time was longer than $60 \mathrm{~s}$, the extraction efficiencies of total phenols decreased with increasing extraction time. In view of this, the range of 40-80 s was used for the optimization of extraction time in the subsequent experiments.

Effect of extraction cycle times: The duration of $60 \mathrm{~s}$ is not enough to completely extract the desired compounds, the repeated experiments were necessary to improve the complete extraction of active compounds in plants. Total phenolic contents gradually increased when the repeated time of the extraction reached three times (Fig. 1c). It is obvious that total phenolic contents of the third one enhance a little. Totally considering the scale of production and time consumption, the three extraction cycles can reach good extraction of total phenols.

\section{Optimization of extraction conditions by response surface method (RSM)}

Box-Behnken design method used for optimization: To further study the interactions between the factors, we optimized liquid-solid ratio, the extraction time and the cycle times by RSM. Table-1 was listed in the experimental factors and levels. The total experimental numbers were 17 , including 5 repeated tests and analyzing factor tests. The results and predicted values were obtained and listed in Table-1. According to experimental results, regression model and analysis of variance were finished and shown in Table-2.

Regression model and analysis ${ }^{12}$ : The Model F-value of 40.67 implies the model is significant. There is only a $0.01 \%$ chance that a "Model F-Value" this large could occur due to noise. Values of "Prob > F" less than 0.0500 indicate model terms are significant. In this case $\mathrm{X}_{1}, \mathrm{X}_{2}, \mathrm{X}_{3}, \mathrm{X}_{1} \mathrm{X}_{3}, \mathrm{X}_{1}^{2}, \mathrm{X}_{2}^{2}$, $\mathrm{X}_{3}{ }^{2}$ are significant model terms. Values greater than 0.1000 indicate the model terms are not significant. If there are many insignificant model terms (not counting those required to support hierarchy), model reduction may improve your model.
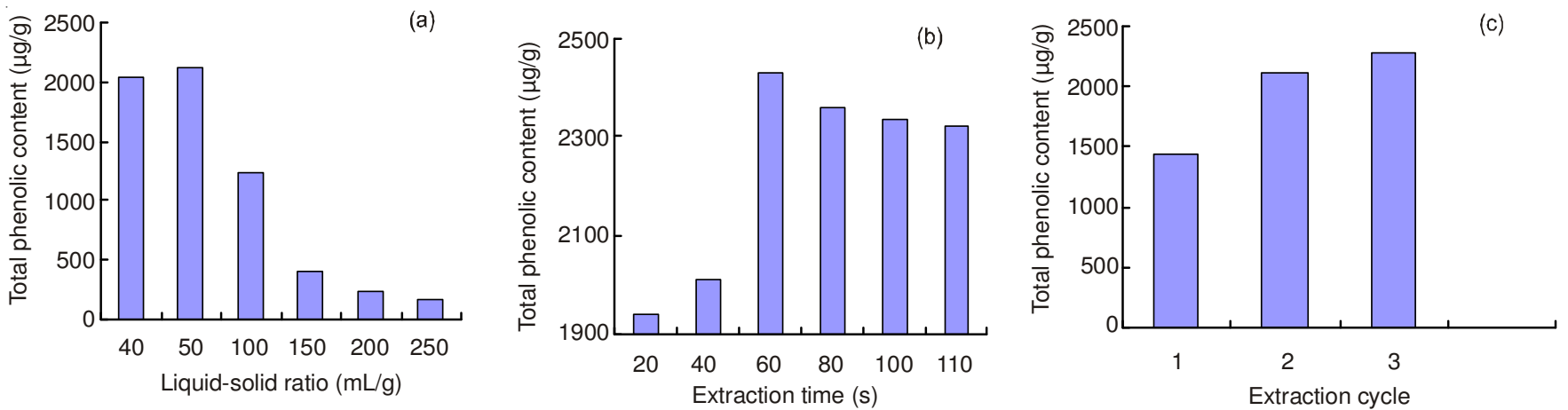

Fig. 1. (a) Effect of liquid-solid ratio on total phenolic content. Sample: 1g, solvent: water, total volume: $50 \mathrm{~mL}$, extraction cycle: 2 times, extraction time: $40 \mathrm{~s}$; (b) Effect of extraction time on total phenolic content. Sample: $1 \mathrm{~g}$, solvent: water, total volume: $50 \mathrm{~mL}$, extraction cycle: 2 times, liquid-solid ratio: $50: 1 \mathrm{~mL} \mathrm{~g}^{-1}$; (c) Effect of extraction cycle on total phenolic content. Sample: $1 \mathrm{~g}$, solvent: water, total volume: $50 \mathrm{~mL}$, liquid-solid ratio: $50: 1$ $\mathrm{mL} \mathrm{g}^{-1}$ 
TABLE-1

BOX-BEHNKEN DESIGN FOR THE OPTIMIZATION OF TOTAL PHENOL EXTRACTION AND RESPONSES

\begin{tabular}{|c|c|c|c|c|c|}
\hline \multirow{2}{*}{ Run } & \multirow{2}{*}{$\begin{array}{c}\text { Factor A }\left(\mathrm{X}_{1}\right) \\
\text { Liquid-solid ratio }\left(\mathrm{mL} \mathrm{g}^{-1}\right)\end{array}$} & \multirow{2}{*}{$\begin{array}{c}\text { Factor B }\left(\mathrm{X}_{2}\right) \\
\text { Extraction time }(\mathrm{s})\end{array}$} & \multirow{2}{*}{$\begin{array}{c}\text { Factor } \mathrm{C}\left(\mathrm{X}_{3}\right) \\
\text { Extraction cycle }\end{array}$} & \multicolumn{2}{|c|}{ Total phenolic content $\left(\mu \mathrm{g} \mathrm{g}^{-1}\right)$} \\
\hline & & & & Actual value & Predicted value \\
\hline 1 & $-1(40)$ & $-1(40)$ & $0(2)$ & 1701.01 & 1666.82 \\
\hline 2 & $1(80)$ & $-1(40)$ & $0(2)$ & 1763.69 & 1740.34 \\
\hline 3 & $-1(40)$ & $1(80)$ & $0(2)$ & 1898.51 & 1921.86 \\
\hline 4 & $1(80)$ & $1(80)$ & $0(2)$ & 2259.33 & 2293.52 \\
\hline 5 & $-1(40)$ & $0(60)$ & $-1(1)$ & 1782.08 & 1746.32 \\
\hline 6 & $1(80)$ & $0(60)$ & $-1(1)$ & 2254.44 & 2207.84 \\
\hline 7 & $-1(40)$ & $0(60)$ & $1(3)$ & 2147.26 & 2193.86 \\
\hline 8 & $1(80)$ & $0(60)$ & $1(3)$ & 2141.77 & 2177.53 \\
\hline 9 & $0(60)$ & $-1(40)$ & $-1(1)$ & 1829.61 & 1899.56 \\
\hline 10 & $0(60)$ & $1(80)$ & $-1(1)$ & 2157.91 & 2170.32 \\
\hline 11 & $0(60)$ & $-1(40)$ & $1(3)$ & 1987.24 & 1974.83 \\
\hline 12 & $0(60)$ & $1(80)$ & $1(3)$ & 2582.22 & 2512.27 \\
\hline 13 & $0(60)$ & $0(60)$ & $0(2)$ & 2534.47 & 2549.34 \\
\hline 14 & $0(60)$ & $0(60)$ & $0(2)$ & 2465.8 & 2549.34 \\
\hline 16 & $0(60)$ & $0(60)$ & $0(2)$ & 2570.69 & 2549.34 \\
\hline 17 & $0(60)$ & $0(60)$ & $0(2)$ & 2576.69 & 2549.34 \\
\hline
\end{tabular}

The "Lack of Fit F-value" of 2.50 implies the Lack of Fit is not significant relative to the pure error. There is a $19.81 \%$ chance that a "Lack of Fit F-value" this large could occur due to noise. The "Pred R-Squared" of 0.7939 is in reasonable agreement with the "Adj R-Squared" of 0.9571. "Adeq Precision" measures the signal to noise ratio. A ratio greater than 4 is desirable. The ratio of 17.209 indicates an adequate signal. This model can be used to navigate the design space. Experimental values of extraction efficiency of total phenol were analyzed by multiple regressions to fit the second order regression equation and the regression model in terms of coded factors was predicted as follows:

$$
\begin{gathered}
Y=-4507.25+111.56 X_{1}+80.13 X_{2}+731.36 X_{3} \\
+0.19 X_{1} X_{2}-5.97 X_{1} X_{3}+3.33 X_{2} X_{3} \\
-0.88 X_{1}^{2}-0.73 X_{2}^{2}-117.17 X_{3}^{2}
\end{gathered}
$$

Method validation: Based on the regression model, the optimum conditions for total phenol extraction conditions were calculated as follows: microwave time 68.34 min, liquid-solid ratio $62.33 \mathrm{~mL} \mathrm{~g}^{-1}$ and three time extraction. At these optimum levels of extraction parameters, the average phenol extraction yield of three repeats was $2592.83 \mu \mathrm{g} \mathrm{g}^{-1}$, which is very close to the predicted value of $2624.29 \mu \mathrm{g} \mathrm{g}^{-1}$. This indicated the regression model was adequate for reflecting the expected optimization.

Free radical scavenging activity of $S$. glauca leaf extract: The scavenging free radical of the aqueous extract of $S$. glauca leaf in comparison with standards VC and BHT for 1,1diphenyl-2-picrylhydrazyl, hydroxyl radical and superoxide anion radical were shown in Fig. 2. The scavenging capacity of 1,1-diphenyl-2-picrylhydrazyl from the extract at $270 \mu \mathrm{g}$ $\mathrm{mL}^{-1}$, which was the highest concentration of the extract in the experimental, was $62.63 \%$. The 1,1-diphenyl-2-picrylhydrazyl assay is being used widely as a preliminary test and it provides useful information on the activity of test compound containing anti-radical ingredient. 1,1-Diphenyl-2-picrylhydrazyl radical, a stable organic radical, gives strong absorption, which was reduced by the extract along with deep purple discoloration and absorbance decrease. Our results indicated that the extract of $S$. glauca leaf exhibits the potently active $\left(\mathrm{IC}_{50}, 198.25 \mu \mathrm{g} \mathrm{mL}^{-1}\right)$ of 1,1-diphenyl-2-picrylhydrazyl radical scavenging action and lower than $\mathrm{IC}_{50}$ of $\mathrm{VC}$ and $\mathrm{BHT}, 8.59$ and $28.85 \mu \mathrm{g} \mathrm{mL}^{-1}$ (Fig. 2a).

An effective anti-hydroxyl radical plant was found for $S$. glauca leaf extracts for the inhibition of hydroxyl radical that gave $50 \%$ inhibition at a concentration of $73.26 \mu \mathrm{g} \mathrm{mL}^{-1}\left(\mathrm{IC}_{50}\right)$, which exhibited lower inhibition capacity for hydroxyl radical radical than standards $\mathrm{VC}$ and $\mathrm{BHT}\left(\mathrm{IC}_{50} 6.69\right.$ and $4.17 \mu \mathrm{g}$ $\mathrm{mL}^{-1}$ ) (Fig. 2b). The scavenging capacity of hydroxyl radical from the extract at $270 \mu \mathrm{g} \mathrm{mL} \mathrm{L}^{-1}$, which was the highest concentration of the extract tested, was $81.66 \%$.

The scavenging activity of superoxide anion radical was measured by the auto-oxidation reaction of pyrogallol, which has maximum absorbance round $320 \mathrm{~nm}$. Fig. 2c showed that the extract of $S$. glauca leaf revealed significant anti-superoxide anion radical capacity compared with $\mathrm{VC}$ and $\mathrm{BHT}$. Its $\mathrm{IC}_{50}$ values are $84.92,13.92$ and $14.11 \mu \mathrm{g} \mathrm{mL} \mathrm{m}^{-1}$, respectively. Superoxide radical, one of the strongest reactive oxygen species generated, is also quenched by the extract, which suggesting that $S$. glauca is also a potential scavenger of superoxide radical. The scavenging capacity of superoxide radical from the extract at $270 \mu \mathrm{g} \mathrm{mL}{ }^{-1}$, which was the highest concentration of the extract tested, was $77.50 \%$.

The scavenging capacity for $\mathrm{H}_{2} \mathrm{O}_{2}, \mathrm{VC}$ and BHT of extract was $182.5,3.83,4.78 \mu \mathrm{g} \mathrm{mL} \mathrm{m}^{-1}\left(\mathrm{IC}_{50}\right.$ ), respectively (Fig. $2 \mathrm{~d}$ ). The scavenging of $\mathrm{H}_{2} \mathrm{O}_{2}$ may be due to phenolic compounds, which donate electron to $\mathrm{H}_{2} \mathrm{O}_{2}$, so that making reducing $\mathrm{H}_{2} \mathrm{O}_{2}$ to $\mathrm{H}_{2} \mathrm{O} . \mathrm{H}_{2} \mathrm{O}_{2}$, one of reactive oxygen species, can be cause by different factors to penetrate biological membranes because of its toxicity from converting to hydroxyl radical radical ${ }^{13}$.

In several studies, most of the extracts of powerful antioxidant activity resulted from higher phenolic content and phenolic compounds are one of natural antioxidants widely contained in natural plants, teas and Chinese medicinal herbs. Meanwhile, the free radical scavenging activity of extracts was also concerned and found to have a strong positive correlation with their total phenolic content. So far the total phenol of water extract from $S$. glauca leaf has higher value (2624.29 


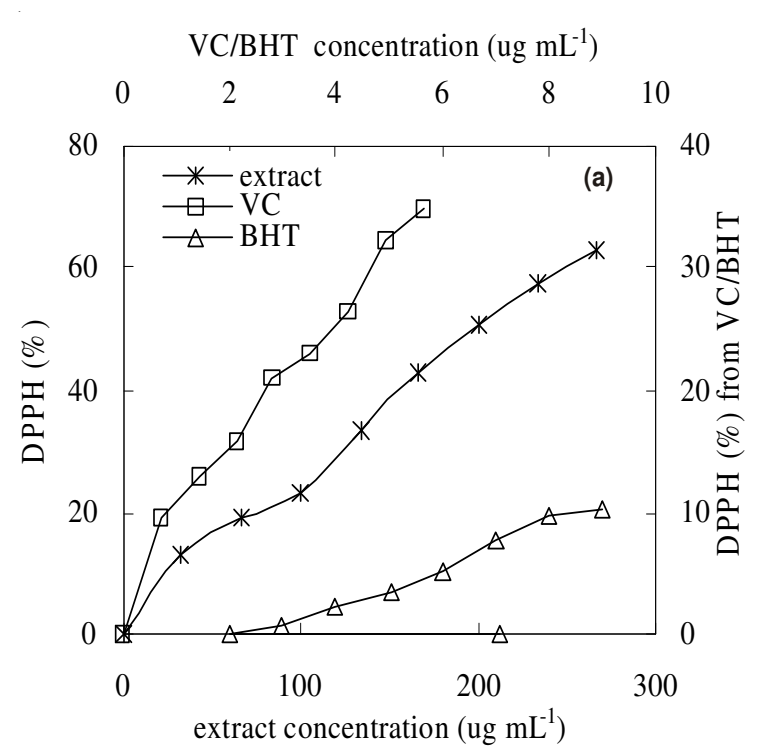

VC/BHT concentration (ug $\left.\mathrm{mL}^{-1}\right)$

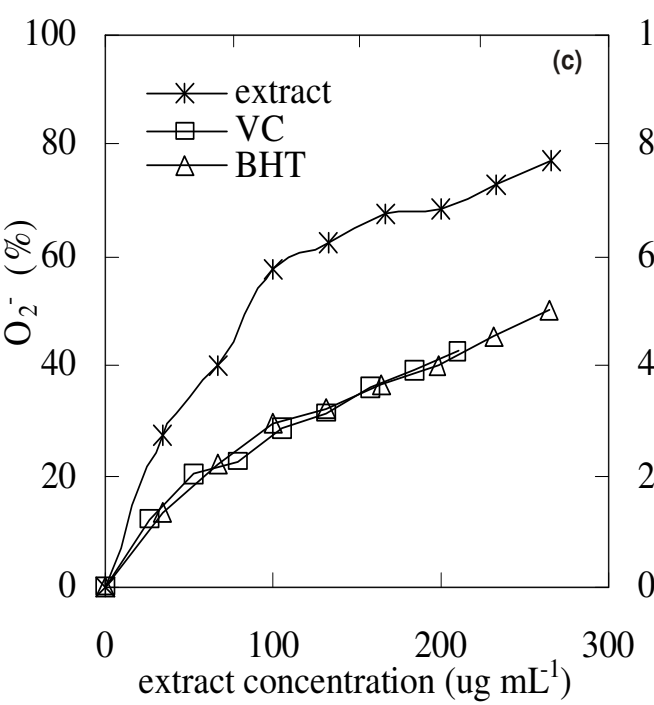

VC/BHT concentration (ug $\left.\mathrm{mL}^{-1}\right)$
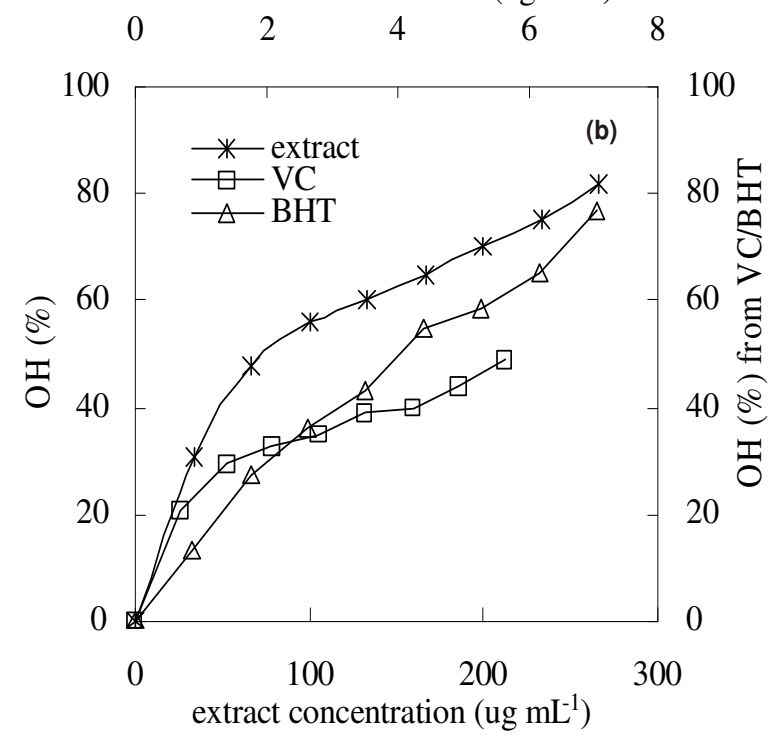

VC/BHT concentration (ug $\mathrm{mL}^{-1}$ )

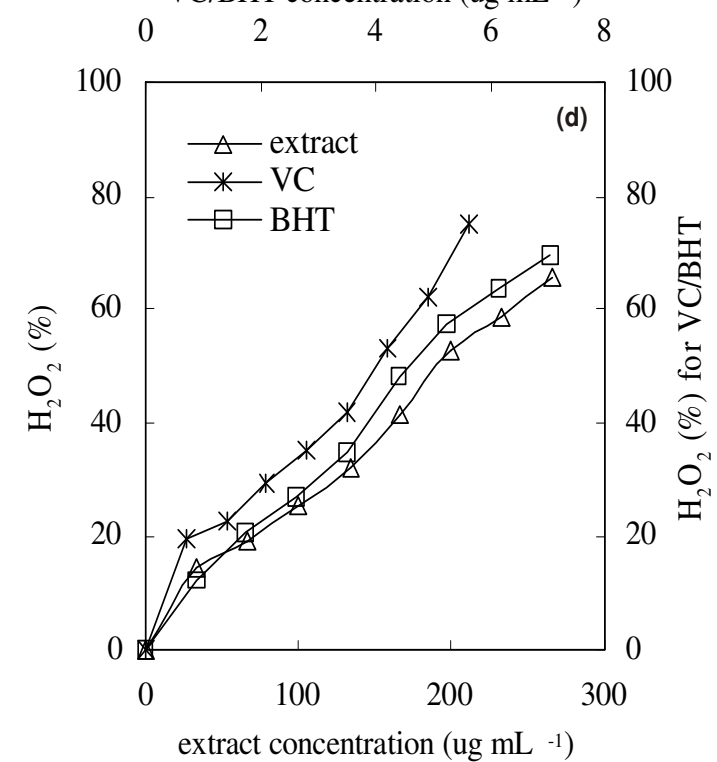

Fig. 2. (a) Activity of scavenging 1,1-diphenyl-2-picrylhydrazyl radical; (b) Activity of scavenging hydroxyl radical radical; (c) Activity of scavenging superoxide anion radical; (d) Activity of scavenging hydrogen peroxide

TABLE-2

RESULTS OF REGRESSION MODEL AND ANALYSIS OF VARIANCE

\begin{tabular}{lccccc}
\hline \multicolumn{1}{c}{ Source } & Sum of squares & Degrees of freedom & Mean square & F-value & Prob $>$ F \\
\hline Model & 1636350.24 & 9 & 181816.69 & 40.67 & $<0.0001$ \\
$\mathrm{X}_{1}$ & 417497.93 & 1 & 417497.93 & 93.39 & $<0.0001$ \\
$\mathrm{X}_{2}$ & 215383.53 & 1 & 215383.53 & 48.18 & 0.0002 \\
$\mathrm{X}_{3}$ & 63488.25 & 1 & 63488.25 & 14.20 & 0.0070 \\
$\mathrm{X}_{1} \mathrm{X}_{2}$ & 22221.86 & 1 & 22221.86 & 4.97 & 0.0610 \\
$\mathrm{X}_{1} \mathrm{X}_{3}$ & 57085.16 & 1 & 57085.16 & 12.77 & 0.0091 \\
$\mathrm{X}_{2} \mathrm{X}_{3}$ & 17779.56 & 1 & 17779.56 & 3.98 & 0.0863 \\
$\mathrm{X}_{1}{ }^{2}$ & 518088.77 & 1 & 518088.77 & 115.89 & $<0.0001$ \\
$\mathrm{X}_{2}$ & 361276.43 & 1 & 361276.43 & 80.81 & $<0.0001$ \\
$\mathrm{X}_{3}{ }^{2}$ & 57804.77 & 1 & 57804.77 & 12.93 & 0.0088 \\
Residual & 31294.18 & 7 & 4470.60 & & \\
Lack of fit & 20421.19 & 3 & 6807.06 & 2.50 & 0.1981 \\
Pure error & 10872.99 & 4 & 2718.25 & & \\
Cor total & 1667644.42 & 16 & Adj $\mathrm{R}^{2}$ & 0.9571 & \\
$\mathrm{R}^{2}$ & 0.9812 & & Adeq Precision & 17.209 & \\
Pred $\mathrm{R}^{2}$ & 0.7939 & & & & \\
\hline
\end{tabular}


$\mu \mathrm{g} \mathrm{g}^{-1}$ ) in similarly agree with stronger free-radical scavenging activity, although it is lower than standards VC and BHT. At present, $S$. glauca is a new plant studied, which is recommended further development on pharmacological activities and practical value as to purify active components for more effectively fighting against disease and being more widely using in various fields.

\section{Conclusion}

The total phenols from S. glauca leaf have been studied. The experimental conditions were optimized by single-factor experiment and RSM. Compared with conventional reference extraction methods, the present approach provides higher extraction efficiency of total phenols. The anti-free radical ability of extract from $S$. glauca leaf is relatively higher than standards VC and BHT. The use of plants or herbs as antioxidants is becoming increasing importance in many fields such as food industry, pharmaceuticals industry and cosmetics. There is an intense interest in plant phenols extract. Various extraction technologies emerge as the times require. Ionic liquid extraction is a new and high efficiency separation technology. In the future, further studies are needed to enhanced extraction efficiency of active components in $S$. glauca and clarify the potential activity in vivo in the management of human diseases.

\section{ACKNOWLEDGEMENTS}

The authors are grateful to Jiangsu Provincial Key Laboratory of Coastal Wetland Bioresources and Environmental Protection (JLCBE12008), the Natural Science Foundation of Education Department of Jiangsu Province (No. 13KJD150005).

\section{REFERENCES}

1. K.F. Zhao, H. Fan, X.Y. Jiang and J. Song, Chin. J. Appl. Environ. Biol., 8, 31 (2002).

2. S. Quideau, Chemistry and Biology of Ellagitannins, An Underestimated Class of Bioactive Plant Polyphenols, World Scientific Publishing, Singapore (2009).

3. C. Manach, A. Mazur and A. Scalbert, Curr. Opin. Lipidol., 16, 77 (2005).

4. M. Herrero, A. Cifuentes and E. Ibañez, Food Chem., 98, 136 (2006).

5. V. Beejmohun, O. Fliniaux, E. Grand, F. Lamblin, L. Bensaddek, P. Christen, J. Kovensky, M. Fliniaux and F. Mesnard, Phytochem. Anal., 18, 275 (2007).

6. V.L. Singleton, R. Orthofer and R.M. Lamuela-Ravent'os, Methods Enzymol., 299, 152 (1999).

7. M. Kammoun, S. Miladi, Y.B. Ali, M. Damak, Y. Gargouri and S. Bezzine, Lipids Health Dis., 10, 30 (2011).

8. X.H. Wang, Afr. J. Microbiol. Res., 6, 6847 (2012).

9. J. Zhishen, T. Mengcheng and W. Jianming, Food Chemistry, 64, 555 (1999).

10. S.L. Cao, H.Y. Zhan, S.Y. Fu and L.H. Chen, Chin. J. Chem. Eng., 15, 132 (2007).

11. O.A. Aiyegoro and A.I. Okoh, BMC Complement. Altern. Med., 10, 21 (2010).

12. C.H. Ma, T.T. Liu, L. Yang, Y.G. Zu, S.Y. Wang and R.R. Zhang, Anal. Chim. Acta, 689, 110 (2011).

13. A. Sroka and W. Cisowski, Food Chem. Toxicol., 41, 753 (2003). 